\title{
O TERMO IDENTIDADE CULTURAL NO MUN- DO CONTEMPORÂNEO SUSTENTA TANTAS IDENTIFICAÇÕES?
}

\author{
LÍCIA FREZZA PISA \\ INSTITUTO FEDERAL DO SUL DE MINAS \\ POUSO ALEGRE, MINAS GERAIS, BRASIL \\ E=MAIL: LICIA.PISA@IFSULDEMINAS.EDU.BR \\ HTTP://DX.DOI.ORG/10.5902/2316882X22146
}




\section{O TERMO IDENTIDADE CULTURAL NO MUNDO CONTEMPORÂNEO SUSTENTA TANTAS IDENTIFICAÇÕES?}

Resumo: O presente trabalho apresenta algumas mudanças sociais ocorridas para que o processo de constituição de identidades se tornasse mais flexível e menos rígido, demonstrando que as instituições que ancoravam as identidades mais fechadas não se sustentam mais. Com isso ocorre uma abertura para um processo de identificações.

Palavras-Chave: identidade; globalização; identificações.

\section{EL TÉRMINO IDENTIDAD CULTURAL EN EL MUNDO CONTEMPORÁ- NEO INCLUYE MUCHAS IDENTIFICACIONES?}

Resumen: Este artículo presenta algunos cambios sociales en el proceso de formación de identidad para ser más flexible y menos rígida, lo que demuestra que las instituciones ancladas más identidades cerradas no tienen más. Es una abertura para un proceso de identificadores.

Palabras clave: identidade; la globalización; la identificación.

THE TERM CULTURAL IDENTITY IN THE CONTEMPORARY WORLD HOLDS MANY IDENTIFICATIONS?

Abstract: This paper presents some social changes to the identity formation process to become more flexible and less rigid, demonstrating that institutions anchored more closed identities do not hold more. It is an opening for identification process.

Keywords: identity; globalization; identification. 


\title{
1 INTRODUÇÃO
}

A questão da identidade, propondo que não há identidades prontas e fechadas, se faz muito importante na sociedade atual por estar presente no dia a dia, no cotidiano das pessoas de formas variadas e com inúmeras possibilidades. O tema é relevante e se apresenta para diversas atividades, desde investigadores sociais, políticos, artistas até empresários multinacionais, pois devido às muitas modificações ocorridas, novos estilos de vida, maior interação comunicacional entre os povos, é necessário que se volte para a valoração, para a compreensão dos núcleos de pertencimento, tanto pequenos quanto os mais amplos, para se descobrir quais discursos, quais imagens significam uma determinada identidade, um preconceito ao outro ou a uma diferença cultural (ECHETO, 2013). Descobrir como os indivíduos se tornam alguém na sociedade, como se colocam, como se identificam, visto que para Echeto (2013) as identidades são produtoras de sentido e emoções.

Mais especificamente, na contemporaneidade, nota-se que, não coincidentemente, a questão da identidade tem se tornado um tema recorrente:

\begin{abstract}
a questão da identidade está sendo extensamente discutida na teoria social. Em essência, o argumento é o seguinte: as velhas identidades, que por tanto tempo estabilizaram o mundo social, estão em declínio, fazendo surgir novas identidades e fragmentando o indivíduo moderno, até aqui visto como um sujeito unificado. A assim chamada "crise de identidade" é vista como parte de um processo mais amplo de mudança, que está deslocando as estruturas e processos centrais das sociedades modernas e abalando os quadros de referência que davam aos indivíduos uma ancoragem estável no mundo social (HALL, 2006, p. 07).
\end{abstract}

Com isso, a identidade não pode ser vista como sendo estável e garantida por si mesma, mas como situações. Porém, é preciso diferenciar papeis de identidades. Os papeis sociais desempenhados pelas pessoas estão ligados às normas de instituições e organizações em sociedade, como ser trabalhador, ser mãe, ser filho, vizinho, ser sindicalista, ser de uma determinada igreja, ser fumante, ser ativista anti-fumo e sua importância depende de negociações e acordos entre os indivíduos e essas instituições. Identidades também podem ser formadas a partir de instituições dominantes, mas devem ter um significado próprio para cada um, ser uma au-

Rev.Cad.Comun. Santa Maria, v.20, n.2, art 1, p.3 de 19, maio/ago.2016 
to-definição. As auto- definições podem se confundir com os papeis, como quando ser pai é a mais importante auto-definiação, por exemplo (CASTELLS, 2008). Porém, as identidades são mais importantes que os papeis por causa de sua autoconstrução e individuação: "identidades organizam significados, enquanto papeis organizam funções [...] Defino significado com a identificação simbólica, por parte de um ator social, da finalidade da ação praticada por tal ator" (CASTELLS, 2008, p. 23).

Para Castells (2008) a identidade é construída por meio de conteúdos simbólicos em negociações, relações de poder, ou seja, "a construção de identidades vale-se da matéria-prima fornecida pela história, geografia, biologia, instituições produtivas e reprodutivas, pela memória coletiva e por fantasias pessoais, pelos aparatos, de poder e revelações de cunho religioso" (p. 23).

Alinhado ao pensamento de identidades sociais e relações simbólicas, a identidade ganha notoriedade na corrente de Estudos Culturais liderada por Stuart Hall (2003), em que propõe pensar a identidade por meio das relações entre o social e o simbólico sem ser reducionista no uso da teoria cultural, ou seja, pensa em deslocamentos da cultura em relação às estruturas sociais de poder que ocorrem por meio de pressões, como guerras de posições, havendo nesse embate constante renovação das novas posições que surgem com novas pressões, não havendo transformação, apenas adequações às novas situações.

Para Echeto, conceituar identidade é complexo, pois os conflitos aparecem no campo teórico e no campo social e o fenômeno identitário é importante tanto para as ciências sociais quanto para a vida social, para o seu funcionamento (2013).

Assim, devemos compreender o que mudou historicamente para fazer com que o fenômeno da identidade despertasse tanto interesse social e acadêmico, pois as velhas identidades que estabilizaram o mundo moderno com um sujeito unificado já não mais sustentam tanta diversidade. As estruturas e os processos sociais que davam referência e ancoragem estável aos indivíduos não mais funcionam.

Hall (2006) propõe três compreensões históricas sobre identidade: o sujeito iluminista, o sujeito sociológico e o sujeito pós-moderno. O sujeito iluminista é um ser humano totalmente centrado, unificado e racional, cuja razão nascia do centro, do núcleo anterior, ou seja, a partir do seu nascimento e desenvolvimento. A identidade do sujeito iluminista era o

Rev.Cad. Comun. Santa Maria, v.20, n.2, art 1, p.4 de 19, maio/ago.2016 
centro essencial do eu (p. 10-11), a pessoa deveria ser um indivíduo soberano. Antes disso, o status, a classificação e a posição na "grande cadeia do ser", ou seja, na ordem secular e divina é que ditavam as normas. Esse indivíduo soberano que surgiu entre o Renascimento do século XVI e o Iluminismo no século XVIII rompeu com o passado, "alguns argumentam que ele foi o motor que colocou todo o sistema social da "modernidade" em movimento" (HALL, 2006, p. 25). O sujeito sociológico nasce com a complexidade do mundo moderno e já não é mais encarado como centro, autônomo ou autossuficiente, visto que seu desenvolvimento se dá na interação com os outros e com os valores, sentidos e símbolos culturais. A identidade do sujeito se dá nas relações em sociedade, por isso traz à tona questões como esfera privada e pública, e costura o sujeito às estruturas vigentes (p. 11). Já o sujeito pós-moderno se apresenta com uma identidade não fixa ou permanente, pois oscila à medida que as representações vão variando. A identidade "é definida historicamente e não biologicamente" (p. 13). Na primeira metade do século XX emergiu uma concepção mais social do sujeito, sustentada pela biologia darwiniana e pelo surgimento das novas ciências sociais, como a sociologia e a psicologia, percebendo o indivíduo em desenvolvimento com grupos e normas coletivas ou mesmo com os papeis sociais sendo negociados.

A identidade sendo histórica compreende um sistema cultural variante e dinâmico em que os sujeitos vão aderindo às novas mudanças à medida em que ocorrem. Porém, antes de compreendermos algumas mudanças relativas à identidade, é preciso entender o que a antecede, ou seja, um modelo de identidade mais rígido e fechado, com poucas possibilidades de manobra.

Para Santos (1993), o projeto sociocultural da modernidade constituiu-se entre os séculos XVI e XVIII com a emergência do capitalismo enquanto modo de produção dominante. $O$ primeiro período do capitalismo ocorreu no século XIX com a expansão da legislação do Estado e a ciência se vinculando ao mercado. No segundo período houve um processo de rematerialização social e política, com a transformação das classes trabaIhadoras, mudanças nos setores produtivos pela acumulação de capital, aumento do setor de serviços, ampliação e fortalecimento social e político das classes médias.

Assim, a classe média se enrijece e passa a formar uma nova burguesia e a diferenciação das identidades para essa nova classe passa a ser a

Rev.Cad.Comun. Santa Maria, v.20, n.2, art 1, p.5 de 19, maio/ago.2016 
seriedade, pois buscou-se separar o imaginário ruidoso e carnavalesco do trabalho manual. Essa modificação entre as classes foi denominada por Moretti (2003) como século sério e contribuiu para se pensar a formação de identidades em países como Inglaterra, França e Alemanha no século XIX.

Do mesmo modo, Rubem Alves (1984) acredita que o século XIX buscou a racionalidade, o entendimento da intenção da razão e, assim, predominaria a funcionalidade. A funcionalidade aparece como aparato tecnológico, como ciência capaz de solucionar os problemas e, com isso as ideologias seriam dispensadas juntamente com as questões de reflexão do pensamento, tempo e espaço: a lógica seria a funcionalidade, em que produção, consumo e homem se unificam e a ideologia desaparece, pois o mundo deve ser organizado e funcional e as pessoas são ajustadas de acordo com as exigências de produção e consumo (p. 12).

Com a sociedade pautada na eficiência funcional surge um homem "função do sistema", em que desaparece a atuação crítica e ideológica, se transforma em coisa, e a identidade aparecerá como estratégia de diferenciação para promover a produção, o consumo, novos estilos de vida, novas formas de pensar, tornando a vida funcional o ideal de vida prazerosa (ALVES, 1984).

O terceiro período do capitalismo ocorreu por volta de 1960 (SANTOS, 1993), com o crescimento econômico mundial impulsionado pelas empresas multinacionais e monopólios transnacionais; pela flexibilização e automatização dos processos produtivos, juntamente com o barateamento dos transportes, descaracterizando as regiões produtoras de certos produtos e a ruralização da indústria; pela crescente diferenciação dos produtos de consumo; pelo abandono da produção de massa aumentando as possibilidades de escolha e a mercadorização da informação. Tudo isso possibilitou a perspectiva da reprodução do capital e fez com que o mercado e a economia tentassem colonizar tanto o Estado quanto a comunidade.

Desse modo, o Estado perdeu a capacidade de regular as esferas de produção e reprodução social, as classes perderam a ideologia de políticas de classe, pois surgiram novas práticas de mobilização social (ecologia, pacifismo etc.). Todas essas transformações apontavam para "uma desregulação global da vida econômica, social e política” (SANTOS, 1993, p. 20).

A cultura da burguesia, então, ressoou na formação do capitalismo

Rev.Cad. Comun. Santa Maria, v.20, n.2, art 1, p.6 de 19, maio/ago.2016 
e da sua cultura de formação de sociedade, pois o centro do indivíduo passou a ser o trabalho, o seu valor econômico, sendo uma das estruturas rígidas que davam sustentação aos indivíduos. Sennett (2006) aponta que na década de 1970 a identidade estava ligada ao trabalho, não necessariamente prazeroso, mas ao trabalho que dava possibilidade de sustentar a família, uma identidade com valor moral bem nos moldes da ética protestante de Max Weber. $O$ trabalho mantinha uma regularidade militar para a prosperidade, quando se fazia mais do que esperavam, e para a punição, quando se saía da linha sem atingir as metas traçadas.

Com o novo capitalismo novas formas de trabalho aparecem, empregos vitalícios diminuem, assim como carreiras em uma única empresa e, com isso, surgem novas formas de se constituir a identidade dos sujeitos ligadas ao trabalho e à funcionalidade. A capacitação passa a não ser um bem durável, forçando as pessoas a aprenderem sempre mais para não caírem na inutilidade. A meritocracia passa a ser um método de promoção dos empregados e uma das qualificações individuais é saber trabaIhar em grupo. Outro modo de avaliação que surge é a ética da perícia, que consiste em fazer o trabalho bem feito por si mesmo (SENNETT, 2006).

Essa busca pela eficiência da força trabalhadora tem o objetivo de aumentar a produtividade e incentivar o consumo, o que gera uma outra percepção com relação aos cidadãos que trabalham com o objetivo de consumir, pois passam a não mais prestar atenção nas coisas, nas sociedades em que vivem, como um certo distanciamento da vida comum para uma vida mais mecânica, pois a cultura da economia capitalista tende a oferecer um modo de vida cada vez mais superficial, no sentido da preocupação com a coletividade. $O$ trabalho deixa de ser algo fixado e orientador, não dá mais visibilidade e status, o cidadão apenas recebe o salário para que se possa consumir os signos e símbolos que dizem sobre o que se é, signos que constroem sua identidade e a repetição dessa ação vai no sentido contrário do aprofundamento, do conhecimento e gera um enfraquecimento político.

Portanto, a identidade na cultura capitalista não é mais uma questão do que fazemos, mas do lugar onde estamos, onde nos integramos. Porém, Sennett (2006) acredita que as novas formas de consumo e o consumo como liberdade (enquanto possibilidade de escolha e individualidade) não libertaram as pessoas, pois o "reino do consumo é teatral" ( $p$. 147). Assim, como fazer as pessoas se unirem em torno de valores e identi-

Rev.Cad.Comun. Santa Maria, v.20, n.2, art 1, p.7 de 19, maio/ago.2016 
dades quando as instituições em que vivem se encontram fragmentadas, como o trabalho?

Cabe enfatizar então que alguns fatores que tornavam a identidade um padrão mais rígido e sem mobilidade agora não mais predominam. Para Santos (1993), há quatro modos de subjetividades e, consequentemente, quatro formas de poder que regiam a constituição dos sujeitos: ser membro de uma família (patriarcado), ser membro de uma classe (exploração), se constituir enquanto indivíduo (rede de subjetividades que se combinam com diversas circunstâncias pessoais e coletivas) e a nação. Além dessas, é possível combinar outras subjetividades, como masculino e feminino, ser membro de alguma associação, grupo esportivo etc. Desse modo, a evolução da identidade sai do sujeito soberano do lluminismo e passa ao sujeito que busca diferenciação na pós-modernidade. Esse sujeito da terceira fase do capitalismo resiste ao conservadorismo, à racionalidade e à funcionalidade.

Nesse sentido, Guiddens (1994) enfatiza a descontinuidade, não havendo apenas um centro, mas centros organizados de forma não linear e uma das contribuições para que isso ocorresse foram as lutas da década de 1960 contra o poder hegemônico e dominador para criar comunidades e grupos de relações pessoais mais diretas, com mais solidariedade, visto que a disputa entre blocos econômicos e guerras ocorriam no momento, assim como revoltas e movimentos estudantis contraculturais e antibelicistas, "lutas pelos direitos civis, os movimentos revolucionários do "Terceiro Mundo", os movimentos pela paz e tudo aquilo que está associado com "1968" (HALL, 2006, p. 44). A contracultura se opunha a certas normas impostas institucionalmente e buscavam se opor a essas ordens por meio de novas crenças, novas alternativas. Com isso, a migração marcou a questão da globalização (SENNETT, 2006) e novos movimentos, motivados pelas necessidades e pela circulação das diferenças passaram a ocorrer, como lutas pela natureza e conservação do próprio espaço, cozinhas comunitárias com o objetivo de sanar a fome das pessoas (organizadas em torno de igrejas e organizações não-governamentais e muitas vezes financiadas com recursos internacionais) e movimentos urbanos em áreas segregadas formando associações ou mesmo gangues (nos EUA) (CASTELLS, 2008).

A globalização, portanto, colaborou para a formação de novas identidades e desestabilização de velhas identidades, principalmente as iden-

Rev.Cad. Comun. Santa Maria, v.20, n.2, art 1, p.8 de 19, maio/ago.2016 
tidades nacionais, que em sociedades mais tradicionais ou em sociedades pré-modernas se constituíam por meio das tribos, religião, região ou povo e passou a ser, na cultura ocidental, designada como cultura nacional, colocando sob o teto do estado-nação as diferenças regionais e étnicas, tornando-se uma poderosa fonte de sistemas de representação (HALL, 2006).

\section{A QUESTÃO DAS IDENTIDADES NACIONAIS E A GLOBALIZAÇÃO}

As identidades nacionais, forma de distinção moderna, se apresentam de maneira fechada, sem muitas oscilações e ligadas apenas a um controlador, ou seja, o Estado. Hall (2006, p. 48) considera que as identidades nacionais não nascem junto quando nós nascemos, mas vão sendo formadas e transformadas no interior da "representação", ou seja, uma comunidade sendo simbólica gera a possibilidade de um sentimento de identidade e de sermos leais a ela ou não.

Para uma compreensão do que seria a narrativa da cultura nacional, Hall (2006) apresenta cinco elementos que reforçam essa ideia: narrativa da nação é contada e recontada nas histórias, literatura, mídia e na cultura popular; narrativa com ênfase na origem das histórias, na continuidade, na tradição e elementos atemporais. A identidade nacional é representada como primordial, "está lá, na verdadeira natureza das coisas" (HALL, 2006, p. 53); narrativa como invenção da tradição, que muitas vezes alegam ser muito antigas, mas na verdade são de origem recente e buscam inculcar valores e normas de comportamento por meio da repetição que, automaticamente vão dando continuidade a esses valores. Por exemplo, "nada parece ser mais antigo e vinculado ao passado imemorial do que a pompa que rodeia a monarquia britânica e suas manifestações cerimoniais públicas. No entanto [...] na sua forma moderna, ela é o produto do final do século XIX e XX" (HALL, 2006, p. 54); narrativa como mito fundacional, em que a origem da nação, do povo, do caráter nacional se perde num passado distante; e a ideia de que a identidade nacional é baseada num povo puro, original.

A identidade nacional, portanto, tende a unificar todos dentro de uma mesma identidade cultural, mesmo tendo classe, gênero e raça diferentes, busca organizar a nação como uma mesma e grande família. Mas podemos pensar que essa identidade nacional esteja anulando as diferen-

Rev.Cad.Comun. Santa Maria, v.20, n.2, art 1, p.9 de 19, maio/ago.2016 
ças culturais, pois uma cultura nacional, não sendo um simples ponto de identificação simbólica e de união para todos, passa a ser uma estrutura de poder cultural (HALL, 2006).

O que temos, então, é que, se as identidades nacionais "costuravam" as diferenças numa única identidade, tendemos a achar que essas identidades estão sendo deslocadas pela grande circulação dos espaços geográficos propiciados pela globalização, porém, se a identidade cultural não é unificada, o que estamos vivenciando agora seria justamente a emancipação das identidades, que estariam sendo "achadas" fora dos sistemas com núcleos duros de classificação. O poder cultural e hegemônico das identidades nacionais está sendo modificado, pois o Estado e as instituições perderam o controle.

Assim, localizamos no século XX uma crise da modernidade que traz a ideia de dissolução das identidades culturais nacionais, mas que já vinha ocorrendo juntamente com outras mudanças e que impactaram o sistema cultural, como a globalização e as mudanças tecnológicas que modificaram a noção de tempo e espaço (HALL, 2006; RUBIN, 2012). O que ocorre é que as identificações mais globais são colocadas acima do nível da cultura nacional e começam a "apagar" as identidades nacionais (HALL, 2006, p. 73). O que favoreceu esse acontecimento foi o fenômeno da migração, principalmente após a segunda guerra mundial, em que pessoas em situações muito precárias procuravam locais onde a sobrevivência e a possibilidade de consumo fossem maiores. Um movimento para fora, com certa correspondência com movimentos da periferia para o centro, em busca de mercadorias, de imagens, de estilos ocidentais e de identidades consumistas, "num dos períodos mais longos e sustentados de migração “não-planejada" da história recente" (HALL, 2006, p. 81).

Como consequência da globalização para as identidades temos que com o crescimento da homogeneização cultural as identidades nacionais estão se desfazendo e novas identidades estão tomando seu lugar, como identidades híbridas; e, por outro lado, identidades nacionais, locais ou particulares acabam sendo reforçadas pela resistência à globalização (HALL, 2006, p. 69).

As identidades híbridas surgem com a circulação da vida social mediada pelas viagens internacionais, pelas trocas de estilos, lugares, imagens da mídia, sistemas de comunicação interligados globalmente que tornam as identidades desvinculadas de tempos, lugares, histórias, tradições etc.

Rev.Cad. Comun. Santa Maria, v.20, n.2, art 1, p.10 de 19, maio/ago.2016 
e parecem "flutuar livremente", tendo na difusão do consumo o seu apoio e o efeito de supermercado cultural (HALL, 2006, p. 75). Os fluxos culturais, entre nações, e o consumismo global criam possibilidades de "identidades partilhadas" - como "consumidores" para os mesmos bens, "clientes" para os mesmos serviços, "públicos" para as mesmas mensagens e imagens - entre pessoas que estão bastante distantes umas das outras no espaço e no tempo. À medida em que as culturas nacionais tornam-se mais expostas às influências externas, é difícil conservar as identidades culturais intactas ou impedir que elas se tornem enfraquecidas através do bombardeamento e da infiltração cultural (HALL, 2006, p. 74).

Se de um lado temos as identidades mais fluídas, por outro, temos a resistência a todo esse movimento de abertura e possibilidades que lutam pela tradição, pela separação, pela distinção entre os povos, baseada numa identidade nacionalista e definida pela oposição ao estrangeiro, que busca recorrer aos espaços físicos e à memória histórica.

Todos os descentramentos oriundos da globalização se mostram como um fator importante para essa descontinuidade dos sujeitos e das identidades. A globalização potencializou e multiplicou as maneiras de se relacionar, de ser e de se expressar. Com a globalização, foi possível integrar e conectar comunidades, organizações, etc., pois foram quebradas as barreiras de espaço e tempo e, inclusive, de fronteiras entre as nações - se a identidade estava ligada ao Estado-nação para ser válida e sólida, com a globalização as nacionalidades se tornaram híbridas e até as instituições que ditavam as normas se tornaram mais maleáveis. Hoje é possível em comunidades distantes, remotas ou mesmo aldeias haver acesso a informações, mensagens, formas de consumo e produtos por meio dos meios de comunicação, há uma interconexão social e uma mudança entre as relações pessoais e cotidianas - na diáspora as identidades se tornam múltiplas.

Hall (2006) aponta que, além desse efeito da globalização para a ocorrência dessas identidades flutuantes, houve um rompimento com a noção de sujeito cartesiano. Os descentramentos do sujeito foram efeitos de:

a) as concepções marxistas de que o homem só faz história de acordo com as possibilidades que lhe são oferecidas e em relação com o outro "e sob as quais eles nasceram, utilizando os recursos materiais e de cultura que lhes foram fornecidos por gerações anteriores" (HALL, 2006, p. 34-

Rev.Cad.Comun. Santa Maria, v.20, n.2, art 1, p.11 de 19, maio/ago.2016 
35);

b) a descoberta do inconsciente por Freud e a negação da identidade inata, pois nossos desejos "são formados com base em processos psíquicos e simbólicos do inconsciente" (HALL, 2006, p. 36);

c) as teorias de Saussure e a noção de estrutura, linguagem e significado social, com o princípio de que sou apenas em relação ao outro, "nós não somos, em nenhum sentido, os autores das afirmações que fazemos ou dos significados que expressamos na língua" (HALL, 2006, p. 40);

d) os estudos de Foucault de docilização dos corpos e vigilância por meio do poder disciplinar, que visa em primeiro lugar a regulação e a vigilância por meio do Governo e em segundo lugar a vigilância do próprio indivíduo com ele mesmo; e

e) os movimentos feministas que, entre outras coisas, questionavam a vida social, a sexualidade e a diferença dos gêneros, lutavam pela igualdade de direitos que tornaram a identidade pessoal uma luta política.

Desse modo, esses processos em mudança, quando colocados em conjunto, representaram uma transformação fundamental em "que somos compelidos a perguntar se não é a própria modernidade que está sendo transformada" (HALL, 2006, p. 09-10). A informação, a comunicação e as redes possibilitadas pela tecnologia da Internet colocam a identidade sempre a ponto de ser testada, experimentada, pois está em constante processo de constituição, o que desestabiliza as identidades. Outro fator importante é o fato de haver um controle e uma fiscalização por meio da rede, esperando certas condutas que podem ser vigiadas por todos (CASTELLS, 2008).

Assim, a identidade ou identidades no mundo globalizado e interconectado passa a ter diferentes tipos de manifestações, marcadas pela história dos grupos, pelas instituições, pelas relações de poder, pelo consumo, por crenças religiosas, por práticas conservadoras ou renovadoras, abertura ou resistência. Desse modo, Castells (2008) define três tipos de identidades.

a) Identidade legitimadora: é produzida pela sociedade civil por meio das relações de poder impostas pelo Estado, na tentativa de racionalizar e expandir sua dominação, mas também por relações de violência simbólica da cultura do espetáculo e da sociedade de simulacros;

b)Identidade de resistência: é criada por aqueles que se encontram em posições ou condições desvalorizadas, estigmatizadas pela lógica de

Rev.Cad. Comun. Santa Maria, v.20, n.2, art 1, p.12 de 19, maio/ago.2016 
uma certa dominação e apresentam mecanismos de resistência com base em princípios diferentes ou opostos daqueles das instituições da sociedade. Nesse sentido, surgem as comunidades e tribos, que carregam o sentido do espaço que ocupam, um sentimento de pertença a um determinado contexto (ex.: tribos de música, de estilos, tribos políticas, etc.). “É provável que seja esse tipo mais importante de construção de identidade em nossa sociedade. Ele dá origem a formas de resistência coletiva diante de uma opressão que, do contrário, não seria suportável [...]" (CASTELLS, 2008, p. 25);

c) Identidade de projeto: surge quando uma nova identidade é constituída redefinindo sua posição na sociedade e buscando uma transformação social. O feminismo é um exemplo, pois questionou o patriarcalismo e toda a sua estrutura de produção, reprodução, sexualidade etc.

O que podemos compreender é que a globalização pode ter aprofundado a crise das ideologias das identidades legitimadoras, como o questionamento e consequente enfraquecimento do modelo de família patriarcal pelo movimento feminista, modificando as estruturas da família e da sexualidade. Isso foi possível devido ao crescimento da economia da informação, as descobertas no processo de reprodução humana (controle sobre a gravidez) e a luta das mulheres para ocupar um espaço público em todas as áreas (CASTELLS, 2008, p. 170). Questionando a sexualidade, o movimento feminista buscou novas funções para os papeis de gênero, pois não compreendia a heterossexualidade como norma e, com isso, buscou uma nova definição para a identidade da mulher, não sendo mais uma categoria deliberada em função do homem.

Com isso, compreendemos que novas estruturas estão sendo experimentadas, não que haja um fim para a família, mas a família patriarcal e nuclear enquanto modelo está sendo testada e novos modos de viver, procriar, educar estão surgindo e o que se busca é redefinir o gênero feminino organizado pelo patriarcalismo, ou seja, "o que está em jogo não é o desaparecimento da família, mas sua profunda diversificação e a mudança do seu sistema de poder" (CASTELLS, 2008, p. 259).

Por isso novas identidades de resistência e de projeto surgem em sociedade, pois, não há mais um único centro de referência para a constituição das identidades (HALL, 2006), a multiplicidade de expressões culturais, sexuais etc. fornecem subsídios para a reconstrução da identidade e a diversidade cultural necessita de respostas multiculturais, com isso inver-

Rev.Cad.Comun. Santa Maria, v.20, n.2, art 1, p.13 de 19, maio/ago.2016 
te-se a lógica da identidade, se antes ela era uma forma política de classe, agora ela passa a ser uma política da diferença (HALL, 2006).

\subsection{Da identidade para as identificações: o papel das tribos}

Maffesoli (1996) compreende a identidade como algo que serviu de suporte teórico para o pensamento ocidental, mas que não serve como valor universal e atemporal, visto que em determinada época ou tempo as modificações aparecem e suscitam a incorporação por parte das pessoas, por isso durante a vida o indivíduo passa por várias modificações que afetam não somente a aparência física como também os sistemas de representações, de relações amicais, amorosas e profissionais. O indivíduo não é homogêneo em si e por si mesmo. Assim, "o sujeito é um 'efeito de composição’, daí seu aspecto compósito e complexo” (p. 305). Echeto (2013) fala em diferenciação diferenciada, em que a comunicação intercultural passa a ser o diálogo para a negociação das diferenças.

Desse modo, Maffesoli propõe a utilização do termo identificação ao invés de identidade: "o que serve de suporte ao individualismo, a lógica da identidade, é algo inteiramente relativo" (1996, p. 301). A identificação atinge uma intensidade quando mistura os diferentes modos de vida, uma "porosidade" que se deixa penetrar por diversas influências, mudanças, representações, culturas. A identidade é pertinente em culturas que apresentam unidade conceitual, centralidade burocrática e clareza de propósitos, assim, pode-se atribuir funções que não serão transgredidas por meio de delimitações e proibições (p. 318). Os movimentos sociais que lutaram por uma identidade como os movimentos operário, estudantil, feminista, homossexual perderam sua legitimidade e acabaram por esvaziar-se, visto que a dinamicidade das identificações é muito mais intensa na atualidade.

Com a circulação entre as massas, faz surgir a configuração de microgrupos, ou tribos: "a massa, ou povo, diferentemente do proletariado ou de outras classes, não se apoiam numa lógica de identidade" (MAFFESOLI, 1987, p. 8). A tribo valoriza o papel de cada pessoa e sua representação dentro do grupo, um processo de desindividualização, contrário ao processo de identidade, em que cada indivíduo atuava com uma função específica dentro de grupos contratuais. Nas tribos, a formação dos grupos se dá por papeis de afetividade. Desse modo, o individualismo da identidade separa e fecha a pessoa em si mesma, sem possibilidades de

Rev.Cad. Comun. Santa Maria, v.20, n.2, art 1, p.14 de 19, maio/ago.2016 
alterações, circulações, já a pessoa (persona) das tribos só existe em relação ao outro. O social passa a ser menos racionalizado. E não-racional não significa ser irracional, mas apenas acionar uma lógica diferente da racionalidade que prevalece desde o lluminismo.

A diferença entre a identidade e tribos também pode ser compreendida da seguinte forma:

\begin{abstract}
No que diz respeito ao conformismo das gerações mais jovens, à paixão pela semelhança, nos grupos, nas 'tribos', aos fenômenos da moda, à cultura padronizada, até e inclusive isto que se pode chamar de unissexualização da aparência, tudo nos leva a dizer que assistimos ao desgaste da ideia de indivíduo dentro de uma massa bem mais indistinta. Esta massa não sabe o que fazer da noção de identidade (individual, nacional, sexual) que foi uma das conquistas mais importantes do burguesismo (MAFFESOLI, 1987, p. 92).
\end{abstract}

A identidade do indivíduo é situada e encontrando uma identidade individual encontramos uma identidade nacional, ou seja, a identidade para Maffesoli (1987) é aceitar que algo é determinado. Assim, tanto as tribos como as discussões com relação ao não-binarismo de gênero compreendem uma indeterminação do sujeito a certas características, modos de ser, comportamentos etc.

Outra diferença entre identidade e tribos se dá pelo social e socialidade. O social marca a identidade: "o indivíduo podia ter uma função na sociedade, e funcionar no âmbito de um partido, de uma associação, de um grupo estável" (MAFFESOLI, 1987, p. 108). A socialidade marca a era das tribos, pois a pessoa representa papeis em diversas áreas da sociedade, como na atividade profissional quanto nos grupos e tribos que participa: "mudando seu figurino, ela vai, de acordo com seus gostos (sexuais, culturais, religiosos, amicais) assumir o seu lugar, a cada dia" (p. 108). Assim, "o social repousa na associação racional de indivíduos que tem uma identidade precisa e uma existência autônoma; a socialidade, por sua vez, se fundamenta na ambiguidade básica da estruturação simbólica" (MAFFESOLI, 1987, p. 135).

Portanto, a estética, os jogos de aparência são uma maneira de experimentar-se, de reconhecer-se e de estar em comum com seu grupo. A questão de o indivíduo ser produtivo deixa de ser uma questão importante e o prazer com a vida passa a ganhar mais espaço, ou seja, a preocupa-

Rev.Cad.Comun. Santa Maria, v.20, n.2, art 1, p.15 de 19, maio/ago.2016 
ção com o corpo, em se dar uma utilidade menos utilitarista ganha espaço em detrimento da funcionalidade do mundo do trabalho. Se a heterogeneização é a regra, com a pluralidade das diferenças culturais, o gueto vai oferecer segurança, por ser um espaço familiar de formação de arquétipos (MAFFESOLI, 1987, p. 188).

Se a tribo fornece segurança, com a interação promovida pela internet surge uma nova aldeia global, portanto, ser solitário não é estar sozinho e, por isso, as identificações por meio da rede são constantes, como também são constantes as novas formações de tribos (FAURY, 1995).

\section{CONSIDERAÇÕES}

Com tantas modificações e possiblidades de identidade e identificações é possível perceber que o capitalismo forneceu um modo de ser sujeito em sociedade, deixando de ser funcional ao sistema (ALVES, 1984) e buscando uma identidade de diferenciação (SENNET, 2006). Enquanto o Estado e as instituições perderam o controle, o homem passou a ter o controle e ser o seu centro, como um ser individual ou mesmo narcisista: "o individualismo (diferente da identidade individual), contudo, pode também ser considerado uma "forma de identidade coletiva" (CASTELLS, 2008, p. 23) encontrada nas tribos. A identidade rígida, conservadora, séria (MORETTI, 2003) não serve mais, não dá conta de contemplar a diversidade de possibilidades globais por meio da circulação de ideias, produtos, consumo etc. propiciados pela experiência entre os migrantes, tanto de países diferentes ou dentro do mesmo país, por meio do contato físico entre as culturas.

As várias possibilidades de identificação entre os sujeitos vão na contramão da racionalidade e funcionalidade, buscando um jeito próprio de se colocar em sociedade. A centralidade dos sujeitos está na constituição do seu próprio centro e pensar em quais são os mecanismos que auxiliam nessa tarefa se faz importante. O processo de midiatização pode ser levando em consideração quando difunde e amplia modelos de comportamento, e refletir sobre o papel dos meios de comunicação na constituição dessas identificações tem sido uma das principais questões no campo dos Estudos Culturais.

Rev.Cad. Comun. Santa Maria, v.20, n.2, art 1, p.16 de 19, maio/ago.2016 
REFERÊNCIAS

ALVES, Rubem A. Tecnologia e humanização. In: Revista Paz e Terra. Rio de Janeiro: Civilização Brasileira. Ano II, n. 8. Setembro. 1968.

CASTELLS, Manuel. O poder da identidade. Tradução de Klauss Brandini Gerhardt. 6.ed. São Paulo: Paz e Terra, 2008.

ECHETO, Víctor Silva. El conflito de las identidades: comunicación e imágenes de la interculturalidad. Barcelona/ES: Institut de la Comunicación, 2013.

GIDDENS, Anthony. Modernidade e identidade pessoal. Lisboa: Celta, 1994.

HALL, Stuart. A identidade cultural na pós-modernidade. Trad. Tomaz Tadeu da Silva; Guaracira Lopes Louro. 11. ed. Rio de Janeiro: DP\&A, 2006.

. Da diáspora: identidades e mediações culturais. Belo Horizonte: Editora UFMG; Brasília: Representações da UNESCO no Brasil, 2003.

MAFFESOLI, Michel. O tempo das tribos: o declínio do individualismo nas sociedades de massa. Tradução Maria de Lourdes Menezes. Rio de Janeiro: Forense-Universitária, 1987.

MAFFESOLI, Michel. No fundo das aparências. Tradução Bertha Halpern Gurovitz. 2.ed. Petrópolis: Vozes, 1996.

MORETTI, Franco. O século sério. In: - O romance. Tradução de Alípio Correa e Sandra Correa. São Paulo: Cosac \& Naify, 2003. Disponível em:<http://novosestudos. uol.com.br/v1/files/uploads/contents/99/20080627_seculo_serio.pdf >. Acesso em: 03 mar. 2015.

RUBIN, Gayle. Pensando o sexo: notas para uma teoria radical das políticas da sexualidade. Revista Estudos Femininos, Florianópolis, vol. 20, n. 2, maio/ago., 2012. Disponível em:< http://www.scielo.br/scielo.php?pid=S0104-026X2012000200010\&script=sci_arttext>. Acesso em 26 fev. 2015. 
CADERNOS DE COMUNICAÇÃO

UNIVERSIDADE FEDERAL DE SANTA MARIA

SANTOS, Boaventura de Sousa. O social e o político na transição pós-moderna. Lua Nova: revista de cultura e política. São Paulo, n. 31, dez. 1993. Disponívelem:<http:// www.scielo.br/scielo.php?pid=S010264451993000300010\&script=sci_arttext $>$. Acesso em 16 ago. 2015.

SENNETT, Richard. A cultura do novo capitalismo. Tradução de Clóvis Marques. Rio de Janeiro: Record, 2006. 


\section{Lícia Frezza Pisa}

Graduada em Comunicação Social - Publicidade e Propaganda, mestre em Linguística e doutorado em Comunicação Social em andamento. Docente do curso de Produção Publicitária do Instituto Federal do Sul de Minas, campus Passos/MG. E-mail: licia.pisa@ifsuldeminas.edu.br.

RECEDIDO EM: 09/05/2016

ACEITO PARA PUBLICAÇÃO: 09/06/2016

Rev.Cad.Comun. Santa Maria, v.20, n.2, art 1, p.19 de 19, maio/ago.2016 